FRÜHMITTELALTERLICHE STUDIEN

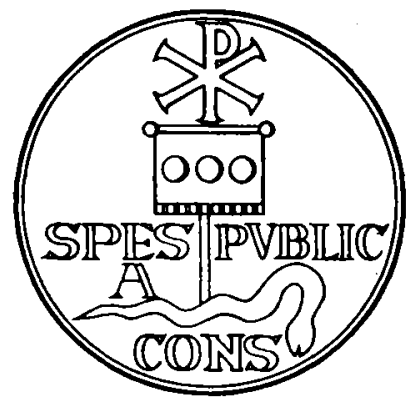





\title{
FRUHMITTELALTERLICHE STUDIEN
}

\author{
Jahrbuch des Instituts für Frühmittelalterforschung \\ der Universität Münster
}

\begin{abstract}
in Zusammenarbeit mit
Hans Belting, Hugo Borger, Dietrich Hofmann, Karl Josef Narr

Friedrich Ohly, Karl Schmid, Ruth Schmidt-Wiegand, Rudolf Schützeichel und Joachim Wollasch
\end{abstract}

herausgegeben von

KARL HAUCK

16. Band

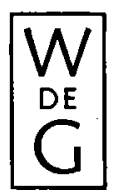

1982 
Dieses Jahrbuch ist im Sonderforschungsbereich 7: 'Mittelalterforschung' entstanden und wurde auf seine Veranlassung unter Verwendung der ihm von der Deutschen Forschungsgemeinschaft zur Verfügung gestellten Mittel gedruckt.

Copyright 1982 by Walter de Gruyter \& Co., vormals G.J. Göschen'sche Verlagshandlung - J. Guttentag, Verlagsbuchhandlung - Georg Reimer - Karl J.Trübner - Veit \& Comp. - Printed in Germany Alle Rechte des Nachdrucks, einschließlich des Rechtes der Herstellung von Photokopien und Mikrofilmen, vorbehalten.

Satz und Druck: Arthur Collignon GmbH, Berlin 30

Bindearbeiten: Lüderitz \& Bauer, Berlin 61 